\title{
CORONAVIRUS INFECTION AND ITS CONTROL THROUGH VARIOUS APPROACHES: A SHORT REVIEW
}

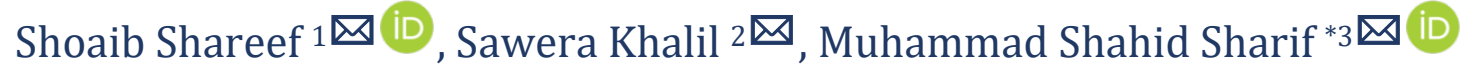 \\ ${ }_{1}^{1}$ Punjab College Bahawalpur, Yazman Road, Model Town A Block, Bahawalpur, Punjab, Pakistan \\ 2 Seerani College, Adda Nai Basti, Lodhran city, Punjab, Pakistan \\ ${ }^{*}$ Department of Chemistry, The Islamia University of Bahawalpur, Punjab, Pakistan
}

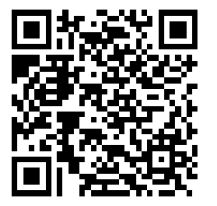

DOI: https://doi.org/10.29121/granthaalayah.v9.i3.2021.3769

Article Type: Research Article

Article Citation: Shoaib Shareef, Sawera Khalil, and Muhammad Shahid Sharif. (2021). CORONAVIRUS INFECTION AND ITS CONTROL THROUGH VARIOUS APPROACHES: A SHORT REVIEW. International Journal of Research GRANTHAALAYAH, 9(3), 97-101. https://doi.org/10.29121/granthaa layah.v9.i3.2021.3769

Received Date: 25 February 2021

Accepted Date: 23 March 2021

Keywords:

Coronavirus Infection

Control

Various Approaches

\begin{abstract}
Coronavirus is a common virus causing very serious issues to public health. This virus, SARS-COV-2, has disseminated worldwide respiratory illness, designated as COVID-19. This viral infection disturbs people in various ways. A lot of people infested due to this virus develop a mild illness and get relief soon without any sort of hospitalization. But mostly, it becomes highly severe later and the patient has to undergo shortening of breath as well as some other chest-related abnormalities like Middle East Respiratory Syndrome (MERS) and Acute Respiratory Syndrome. In this manuscript, we have discussed multiple areas like symptomatology, management approaches including Homoeopathic and Allopathic (drugs) treatments, plus vaccination. Lastly, we have put in the conclusion of overall literature, and most importantly implicated or suggested certain new research areas for the researchers to explore which may assist in preventing further spread of this threatening syndrome now and in the future.
\end{abstract}

\section{INTRODUCTION}

\subsection{SYMPTOMS OF CORONAVIRUS INFECTION}

In patients with pneumonia caused by SARS-CoV-2 (new coronavirus pneumonia), the most common indicator or symptom observed in the patients was fever pursued by cough. The ground-glass opacity of the lungs was the common judgment from a CT scan of the chest. One of the cases of SARS-CoV-2 pneumonia in the United States of America is verifying good to Remdesivir, which is still in the trial period in China (Cheng Lai et al., 2020). There is not merely one coronavirus species but are the six that become the source of disease to human such as, common cold, acute respiratory syndrome as well as the Middle East Respiratory Syndrome. In January 2020, scientists from Wuhan city of China secluded a new coronavirus (SARS-CoV-2), a causative agent for an upsurge of anonymous pneumonia that had not been originated in humans earlier. The spreading of this novel coronavirus takes place through person-to-person contact, respiratory droplets, plus by touching anything contaminated by the virus. The symptomatology of this viral infection mostly includes fever, cough, breathing trouble, pneumonia, and severe acute

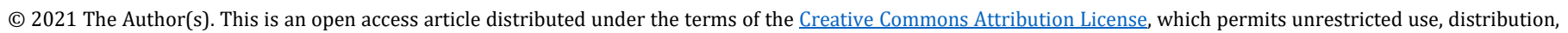
and reproduction in any medium, provided the original author and source are credited. 
Coronavirus Infection and Its Control Through Various Approaches: A Short Review

respiratory syndrome. Those people who are older age and partaking in poor immunity are at a larger threat of this infection (Ramesh et al., 2020).

\section{MANAGEMENT STRATEGIES}

Numerous defensive approaches, as well as non-pharmaceutical interventions, are in use to limit the spreading of disease i.e. watchful infection control, the isolation of patients, and more importantly, is social distancing. Management is chiefly assisting people with the help of oxygen therapy that is evidencing useful in the treatment procedure. Moreover, Corticosteroids plus antivirals therapy have also been verified for a supportive role in critical management strategies (Nicola et al., 2020). This disease affected the entire world, and many myths are socializing about its diagnostic procedures. The option for analysis should be reliant on clinical and epidemiological factors and associated with an appraisal of the chances of this viral infection. To detect COVID-19, various speedy diagnostic and serological tests are in use now. However, the authenticity of such newly marketed tests is not good enough yet. For that reason, it is not suggested any such immune chromatographic or serological speedy screening tests to inspect SARS-CoV-2 contagions. In case to detect COVID-19, PCR (Polymerase Chain Reaction) is a more reliable and authentic diagnostic test, which is a molecular-based examination to conform to SARS-CoV-2. Obliteration of highly transmittable SARS-CoV-2 Virus that is the main source for this newly emerged deadly pandemic (COVID-19) dictate our attention and understanding is desired regarding the way as well as a mode of transmission throughout the whole world. Certain precautionary measures naming as hand-washing, staying at the home plus upholding the social distance are attested as effective and instant way-outs to protect humans from this secret enemy (Sajid and Amgain, 2020). A person having a travel history from COVID-19 affected countries in the last 14 days or a person whose COVID-19 test is positive are suspect cases and need evaluation (Ramesh et al., 2020).

\subsection{ROLE OF HOMEOPATHY IN CONTROL OF CORONAVIRUS}

A wide medical practice has a significant role in the immune-boosting effect of Homoeopathic medicines as well as the hindrance of viral infection. During several disease outbreaks like Cholera, Chikungunya, Japanese Encephalitis, and Dengue Fever, etc. the Genus Epidemicus has been used to control the spread of disease and shows good results. Given the medical achievement in those severe contagious diseases, Homoeopathy as an adjuvant to the standard of care should be evaluated for the administration of COVID-19. The Ministry of Ayurveda, Yoga \& Naturopathy, Unani, Siddha, and Homoeopathy (AYUSH) have recommended the use of Arsenicum album-30 for its doable role in stopping the COVID-19 virus (N Parikh and D Parikh., 2020).

Antimonium Tart acts directly on mucous membrane producing catarrhal swelling of larynx trachea and bronchi causing amassing of mucous. The Nerve center is affected by this respiratory toxin, causing the severe venous obstruction. By this muscle relaxes and respiration is affected more. It damages the nerves which make emesis...... Dr. W. H. Burt: Physiological Materia Medica (Burt and William H, 1881). In Lecture Notes on Materia Medica, Dr. J.T.Kent says that in Antimonium Tart the beginning of a disease is similar to common upper respiratory tract infection followed by temperature with a dry cough but afterward the disease moves to the lower respiratory portion where a patient doesn't respond to any other medication Dr. Kent calls this poor response of a person to the disease and in that case the respiratory distress starts. Thus it is very good therapy for poor response where the patient immune system stops working and a lethal rattle in the chest causes death (Boericke, 2020).

Dr. William Boericke in his books wrote regarding the antihelminthic characteristics of Antimonium Tart, which stimulates the oxidizing action on the shielding cover of a parasite. The outer layer of the coronavirus also has a lipid coat which can be ruined by Antimonium Tart. Thus we present that Antimonium Tart can be used as a prophylactic and therapeutic involvement in COVID 19 disease based on existing literature and information and its medical use.

\subsection{TREATMENT VIA ALLOPATHIC MEDICINE AND VACCINATION}

Treatment in coronavirus according to allopathic, included intravenous infusion of fluid, oxygen therapy, and life support system in serious cases. It is necessary to contact the doctor immediately if someone has symptoms of the virus-like flu, fever, and breathlessness. This virus is familiar to the human immunodeficiency virus (HIV) in terms of virus replication and proteins. Different managing medicines are present to clear and manage in vitro action 
in opposition to SARS-Cov and MERS-Cov (Savarino et al., 2003). Some drugs being used to get relief from coronavirus infection, and their functions are discussed (see Table 1 for detail). The two vaccines such as EUAs Pfizer-BioNTec and Moderna - are until now the only products available to Americans. Pfizer's vaccine is given by the FDA for people 16 and older, making it the first coronavirus vaccine presented to the American. The second one is Moderna's vaccine that has now been approved for people 18 and older. Both these vaccines have been found highly effective for preventing COVID-19 in clinical examination participants. FDA analysis shows that regardless of age, race, or other risks of serious illness due to infection, Pfizer BioNTech's two-dose vaccine can effectively resist 95\% of COVID-19. And it turns out that Moderna can produce approximately 94.5\% of COVID-19 for people of all ages, genders, and races (Nania et al,. 2021). Multiple vaccines and their percentage relief is exhibited below (Fig. 1).

Table 1: Multiple allopathic medicines (drugs) being used to halt deadly coronaviruses

\begin{tabular}{|c|c|c|c|}
\hline $\begin{array}{c}\text { S. } \\
\text { No }\end{array}$ & $\begin{array}{c}\text { Names of allopathic } \\
\text { medicine }\end{array}$ & Function for Covid-19 disease & Citations \\
\hline 1 & Remdesivir & $\begin{array}{c}\text { It is a very potent antiviral drug that de-accelerates the } \\
\text { RNA viral contamination of SAS-Cov-2. }\end{array}$ & $\begin{array}{c}\text { (Kong et al., 2020; } \\
\text { Gordon et al., 2020) }\end{array}$ \\
\hline 2 & Ivermectin & $\begin{array}{c}\text { This drug is reported to have in vitro antiviral function } \\
\text { against a wide-ranging coronavirus }\end{array}$ & $\begin{array}{c}\text { Kagstaff et al., 2012; } \\
\text { Kosyna et al., 2015) }\end{array}$ \\
\hline 3 & Chloroquine & $\begin{array}{c}\text { It effectively works for in vitro inhibition of novel } \\
\text { COVID-19 virus }\end{array}$ & (Wang et al., 2020) \\
\hline 4 & $\begin{array}{c}\text { Hydroxychloroquine } \\
\text { (HCQ) }\end{array}$ & $\begin{array}{c}\text { Efficient to reduce SARS-CoV-2 infection } \\
\text { (Shittu and Affolami., } \\
\text { 2020) }\end{array}$ & (Hung et al., 2020) \\
\hline 5 & $\begin{array}{c}\text { Lopinavir/Ritonavir } \\
\text { combination of both antiviral drugs along with } \\
\text { interferon is more favorable. }\end{array}$ & (Deng et al., 2020 \\
\hline 5 & Arbidol (Umifenovir) & $\begin{array}{c}\text { The antiviral action of Umifenovir against SARS-CoV-2 } \\
\text { has been approved in vitro }\end{array}$ & (S) \\
\hline
\end{tabular}

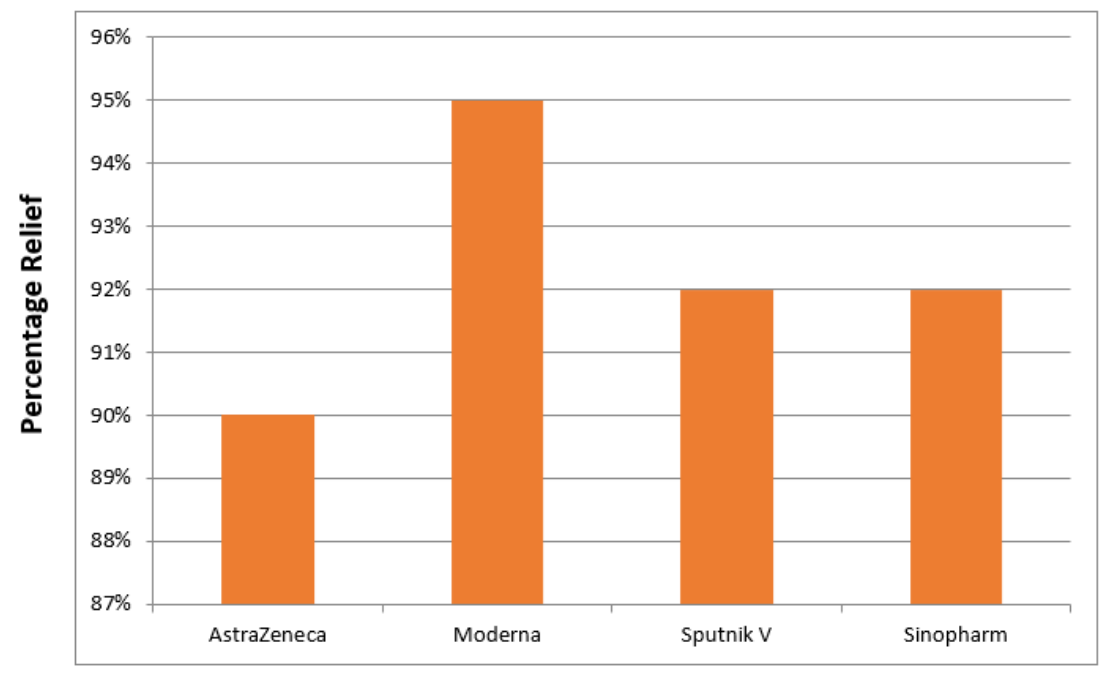

Names of vaccines

Figure 1: Efficiency or relief of different vaccines (\% relief) against coronavirus infection

\section{CONCLUSION AND RECOMMENDATIONS}

Coronavirus is a contagious disease. From health experts' point of view, it was originated from bats and later was transmitted to humans. It causes diseases such as Middle East Respiratory Syndrome and Acute Respiratory Syndrome. Sometimes it becomes deadly and medical assistance is needed but in many cases, patients recover without any hospitalization. Six species of coronavirus are known to cause diseases in humans such as the common cold, fever, etc. In China, scientists discovered a new coronavirus in January 2020. This virus was responsible for the 
outburst of unidentified pneumonia which was not found in humans before. Its incubation period lies between 2 to14 days. Seclusion of patients, careful control of disease, and social distancing can minimize the spread of this disease. Corticosteroids and antiviral therapy are proving helpful in their control. To detect COVID-19, many tests are in use but the most reliable test for its detection is PCR (polymerase chain reaction). To save ourselves from this deadly virus, we should follow safety measures like proper hand washing, staying at home, and maintaining social distance. Homeopathy also has a significant role in this pandemic. The homeopathic medicine Arsenicum album-30 can be proved helpful in controlling COVID-19. The upper layer of coronavirus is made up of a lipid coat that can be destroyed by homeopathic medicine named Antimonium Tart. Allopathic treatment in coronavirus includes an intravenous infusion of fluid and oxygen therapy. Some vaccines have now also been introduced, such as Pfizer's which is given by FDA for people 16 or older. The second one is Moderna's vaccine which is approved now for use for people 18 or older.

By studying literature, I believe that by boosting immunity we can be protected by diseases. The immune system is the best because it increases the body's natural ability to defend against pathogens. Boosting our immunity, obeying safety measures such as proper handwashing, avoid close contact with a person who is sick, avoiding crowded places, and maintaining social distance can help control Covid-19 infection. The role of homeopathy can help control the virus such as Arsenicum album-30 can help in preventing coronavirus. Washing our hands frequently with alcohol-based hand wash because it kills the germs as well as viruses that may be present on our hands. We should cover our mouth and nose with a bent elbow as well as by tissue during coughing and sneezing. Clean those surfaces repeatedly which are used regularly. We should avoid touching our mouth, eyes, and nose. The main point is that by following good respiratory hygiene, we not only protect ourselves but also other people from viruses, which cause colds, flue, and COVID-19.

There are some areas of research that are not well explored and can be impacted by the COVID-19 in present or in the future. These areas include vaccine development, medication therapy, healthcare and equipment, social, economic, environmental, sustainability, psychiatric, information technology revolution, awareness workshops, biological warfare, and psychological issues. I am certain that if researchers explore these areas and equip each domain with health facilitation then we can halt coronavirus infection to spread worldwide.

\section{SOURCES OF FUNDING}

This research received no specific grant from any funding agency in the public, commercial, or not-for-profit sectors.

\section{CONFLICT OF INTEREST}

The author have declared that no competing interests exist.

\section{ACKNOWLEDGMENT}

We thank Mr. Muhammad Zahid Sharif (a Ph.D. student) for his efforts for multiple revisions and suggestions to improve this manuscript.

\section{REFERENCES}

[1] Boericke, W. 2020. Homoeopathic Materia Medica. Retrieved 27 April 2020, from http://www.homeoint.org/books/boericmm/ 15. James Tyler Kent. Lectures on Homoeopathic material Medica; $\quad$ Retrieved $\quad 28 \quad$ April, $\quad 2020$ from https://homeopathybulgaria.org/todormed/JAMES\%20TYLER\%20KENTLectures\%200N\%20HOMEOPAT HIC\%20MATERIA \%20MEDICA.pdf

[2] Burt, William H. Physiological materia medica, containing all that is known of the physiological action of our remedies; together with their characteristic indications and pharmacology. (Chicago, Gross \& Delbridge, 1881. 
[3] Deng, L., Li, C., Zeng, Q., Liu, X., Li, X., Zhang, H., Hong, Z., Xia, J. (2020). Arbidol combined with LPV/r versus LPV/r alone against Corona Virus Disease 2019: A retrospective cohort study. J. Infect. 81, e1- e5, https://doi.org/10.1016/j.jinf.2020.03.002

[4] Gordon, C.J., Tchesnokov, Feng, J.Y. (2020). The antiviral compound remdesivir potently inhibits RNAdependent RNA polymerase from Middle East respiratory syndrome coronavirus. Journal of Biological Chemistry. 295: 4773-4779. https://doi.org/10.1074/jbc.AC120.013056.

[5] Hung, I. F., Lung, K. C., Tso, E. Y et al. (2020). Triple combination of interferon beta-1b, lopinavir-ritonavir, and ribavirin in the treatment of patients admitted to hospital with COVID-19: an open-label, randomised, phase 2 trial. Lancet, 395, 1695-1704, https://doi.org/10.1016/S0140-6736(20)31042-4

[6] Kong, R., Yang, G et al. (2020). COVID-19 docking server: an interactive server for docking small molecules, peptides and antibodies against potential targets of COVID-19. arXiv preprint arXiv:2003.00163.https://doi.org/10.1093/bioinformatics/btaa645.

[7] Kosyna, F.K., Nagel, M., Kluxen, L. et al. (2015). The importin $\alpha / \beta$-specific inhibitor ivermectin affects HIFdependent hypoxia response pathways. Biological Chemistry. 396: 1357-1367. https://doi.org/10.1515/hsz2015-0171.

[8] Lai, C.C., Shih, T.P., Ko, W.C., Tang, H.J. and Hsueh, P.R. (2020). Severe acute respiratory syndrome coronavirus 2 (SARS-CoV-2) and corona virus disease-2019 (COVID-19): the epidemic and the challenges. International journal of antimicrobial agents. 105924.

[9] Nania,R., Christina, I. and Dena, B. (2021). What to Know About the Coronavirus Vaccines. AARP. https://www.aarp.org/health/conditions-treatments/info-2020/coronavirus-vaccine-research.html

[10] Nicola, M., O’Neill, N., Sohrabi, C., Khan, M., Agha, M. and Agha, R. (2020). Evidence based management guideline for the COVID-19 pandemic-review article. International Journal of Surgery. 77: 206-216.

[11] Parikh, N. and Parikh, D. (2020). Role of homoeopathy in COVID-19 Management-A clinical experience. World Journal of Pharmaceutical Research. 9(5): 2459-2466.

[12] Ramesh, N., Siddaiah, A. and Joseph, B. (2020). Tackling corona virus disease 2019 (COVID 19) in workplaces. Indian Journal of Occupational and Environmental Medicine. 24(1): 16-18.

[13] Sajed, A.N. and Amgain, K. (2020). Corona virus disease (COVID-19) outbreak and the strategy for prevention. Europasian Journal of Medical Sciences. 2(1): 1-3.

[14] Shittu M.O., Afolami O.I. (2020). Improving the efficacy of chloroquine and hydroxychloroquine against SARSCoV-2 may require zinc additives- a better synergy for future COVID-19 clinical trials. Infez Med. 28: 192-197.

[15] Talwar, S., Sood, S., Kumar, J., Chauhan, R., Sharma, M. and Tuli, H.S. (2020). Ayurveda and Allopathic Therapeutic Strategies in Coronavirus Pandemic Treatment 2020. Current pharmacology reports, pp.1-10.s

[16] Wagstaff K.M, Sivakumaran H, Heaton S.M et al. (2012). Ivermectin is a specific inhibitor of importin $\alpha / \beta-$ mediated nuclear importable to inhibit replication of HIV-1 and dengue virus. Biochemistry Journal. 443: 851856. https://doi.org/10.1042/BJ20120150.

[17] Wang M., Cao, R., Zhang, L et al. (2020). Remdesivir and chloroquine effectively inhibit the recently emerged novel coronavirus (2019-nCoV) in vitro. Cell Research. 30: 269-271. https://doi.org/10.1038/s41422-0200282-0. 